\title{
Analisis Biomekanika Open Smash Bola Voli di Club Bina Taruna Semarang
}

\author{
Choirul Anwar ${ }^{1 凶}$, Bertika Kusuma $P^{2}$, Ibnu Fatkhu ${ }^{3}$
}

Jurusan Pendidikan Jasmani Kesehatan dan Rekreasi, Fakultas Pendidikan IImu Pengetahuan Sosial dan Keolahragaan, Universitas PGRI Semarang,

choirulpjkrupgris@gmail.com

\section{Article Info}

History Articles

Submitted : 21 Januari 2020

Revewed : 15 April 2020

Accepted : 18 Juni 2020

\section{Keywords}

Analisis Gerak; Bola Voli; Smash

\begin{abstract}
Abstrak
Peneltian ini bertujuan untuk mengetahui hasil dari analisis biomekanika open smash bola voli di club Bina Taruna Semarang. Penelitian ini merupakan penelitian kualitatif menggunakan metode analisis gerak smash, teknik pengambilan sampel dalam penelitian ini menggunakan purposive sampling yaitu atlet club Bina Taruna Semarang sebanyak 10 atlet, teknik pengumpulan data dalam penelitian ini menggunakan tri angulasi data, diantaranya wawancara, observasi dan didokumentasikan dalam bentuk video dan diteliti menggunakan aplikasi software dartfish. Hasil analisis dartfish, ada 5 atlet yang melakukan impact bola dengan jangkauan paling atas, namun faktor penyebab kurangnya hasil smash yaitu lecutan tubuh cenderung tidak kebawah mengikuti arah bola, sehingga power pukulan tidak keras dan kurang tajam. Kesimpulan dari penelitian ini secara keseluruhan atlet club Bina Taruna Semarang melakukan gerakan smash masih kurang maksimal, atlet club Bina Taruna Semarang masih kurang baik dalam bagian impact. serta pendaratan dengan salah satu kaki terlebih dahulu faktor penyebab pendaratan smash tidak seimbang.
\end{abstract}

\begin{abstract}
The background of this research is to find out the shortcomings of Bina Taruna Semarang club athletes in performing smash movement techniques that have not been maximized, a problem will be formulated to be investigated, namely how the analysis of open smash biomechanics in volleyball, from this research, aims to find out the results of the open biomechanics analysis volleyball smash at the Semarang Bina Taruna club. This research is a qualitative study using a smash motion analysis method, the sampling technique in this study uses purposive sampling, namely the 10 athletes club Semarang Bina Taruna club, data collection techniques in this study using tri angulation of data, including interviews, observations and documented in the form of video and examined using the dartfish software application. Analysis of dartfish, there are 5 athletes who impact the ball with the highest range, but the factors that cause the lack of smash results are that the body whip tends not to go downward following the direction of the ball, so the power punch is not hard and less sharp. The conclusion of this study as a whole, the Bina Taruna Semarang club athletes doing smash movements are still not optimal, the Bina Taruna Semarang club athletes are still not good in the impact section. as well as landing with one foot first the factors causing the unbalanced smash landing.
\end{abstract}

(C) 2020 Semarang State University

\footnotetext{
Alamat korespondensi :

Alamat: Gedung Pusat Lt.3 Universitas PGRI Semarang

Jl. Lontar No. 1 - Dr. Cipto Semarang

E-mail : choirulpjkrupgris@gmail.com
} 


\section{PENDAHULUAN}

Olahraga merupakan suatu kebutuhan tersendiri bagi kehidupan manusia kapanpun dan dimanapun. Kehidupan moderen sekarang menyebabkan manusia semakin sadar akan pentingnya olahraga. Kesadaran ini mempengaruhi perkembangan pengetahuan dan minat pada olahraga semakin pesat, baik sebagai suatu hobi, tontonan, rekreasi, kebugaran, kesehatan maupun mata pencaharian (Abraham, 2010).

Bola voli adalah olahraga yang dilakukan dengan cara memvolley bola di udara melewati jaring/net agar dapat jatuh di dalam lapangan lawan untuk mencari kemenangan bermain. Memvolley dan memantulkan bola di udara harus mempergunakan bagian tubuh pinggang ke atas serta bersih pantulannya. Satu regu terdiri dari enam orang dan paling banyak dapat memainkan bola di lapangan sendiri tiga kali, dengan peraturan setiap pemain tidak diperbolehkan memainkan bola di udara dua kali berturut-turut (Suharno HP, 1982:4).

Permainan ini dimainkan oleh 2 tim yang masing-masing terdiri dari 6 orang pemain dan berlomba-lomba mencapai angka 25 terlebih dahulu. Dalam sebuah tim, terdapat 4 peran penting, yaitu tosser (atau setter), spiker (smash), libero, dan defender (pemain bertahan). Tosser atau pengumpan adalah orang yang bertugas untuk mengumpankan bola kepada rekan-rekannya dan mengatur jalannya permainan. Spiker bertugas untuk memukul bola agar jatuh di daerah pertahanan lawan. Libero adalah pemain bertahan yang bisa bebas keluar dan masuk tetapi tidak boleh men-smash bola ke seberang net. Defender adalah pemain yang bertahan untuk menerima serangan dari lawan (Winarno, DKK, 2013: 31).
Biomekanika adalah ilmu tentang gaya dalam dan gaya luar yang bekerja pada badan manusia serta pengaruh-pengaruh yang dihasilkan oleh gaya-gaya tersebut (Sudarmada, Kusuma, 2015: 02).

Ada macam-macam gerak/teknik yang digunakan, menurut (M Yunus, 1992:68) dalam (Winarno dkk, 2013: 11). Teknik adalah prosedur yang dikembangkan berdasarkan praktek, dan bertujuan mencari penyelesaian suatu problema pergerakan tertentu dengan cara yang paling ekonomis dan berguna. Teknik dasar bermain bola voli yaitu : servis, passing, umpan (set up), smash (spike), dan bendungan (block) .

Open smash adalah cara melakukan serangan dengan memukul bola saat melambung tinggi di atas net, Usahakan bola selama menempuh lintasannya berjarak $20-30 \mathrm{~cm}$ dari net. Jarak bola jatuh berada di sekitar daerah yang letaknya sejauh setengah jarak dari yang diukur di tempat set-uper berdiri sampai kepada titik proyeksi ditempat permulaan spiker mengambil awalan. Seorang pemain utuk dapat melakukan smash normal harus memperhatikan proses pelaksanaan smash. Proses melakukan smash dapat dibagi dalam empat tahap: saat mengambil awalan, saat melakukan tolakan, saat melakukan pukulan, dan saat melakukan pendaratan. Perbedaan terletak pada perkenaan bola dan ketinggian bola, teknik dilakukan dengan pemain yang akan melakukan spiker lebih dahulu bergerak sebelum bola sampai pada set-uper. Set-uper memberikan bola tidak lebih dari 2 meter di atas net. (Winarno dkk, 2013: 119).

Menurut Winarno dkk (2013: 119-121) ada empat tahap gerakan dalam melakukan smash yaitu: langkah awal (lai menghampiri), sikap menolak, sikap pukulan (perkenaan bola), sikap mendarat. 
Club atau Persatuan Bola Voli Bina Taruna Semarang berdiri pada tahun 1990 oleh pak Hartono S.T. Dulu tempat latihan berada di gor (perum bea cukai) di Jl. Pandean Lamper. Tetapi sejak pemindah alih kepelatihan pada tahun 2008 tempat latihan berpindah di gor kedugmundu yang beralamat di J. Kedungmundu Raya No. 123a, Tandang Tembalang. Dengan susunan pengurus yang baru, diketuai oleh bapak Hariyadi, S. T.; bapak Haryanto, S.T sebagai sekertaris; ibu Astiningtyas, S. Kom sebagai bendahara; bapak Hartono sebagai pembina; dan bapak Ahmad Sobari sebagai seksi kepelatihan. Awal mula didirikannya PBV Bina Taruna adalah untuk menyalurkan bakat bapak Hariyadi, bapak Haryanto, dan bapak sobari yang dahulunya adalah atlet PDAM kota Semarang. Untuk membantu kelancaran setiap latihan club Bina Taruna Semarang juga memiliki lima asisten pelatih diantaranya: Bayu, Dinantyo, Herminto, Wisnu, dan Alfin. Jumlah atlet sampai sekarang mencapai sekitar 100 lebih atlet. Untuk kategori PBV. Bina Taruna Semarang memiliki empat kategori usia, yaitu: usia 12, usia 15, usia 17, dan senior. Program latihan dilakukan seminggu tiga kali pagi dan sore hari. Sedangkan prestasi yang pernah diraih PBV. Bina Taruna Semarang adalah juara 2 PERVIS (kategori umum), juara 2 PERVIS (usia 15), dan juara 2 PERVIS (usia 17) dalam tournament PBVSI tingkat kota Semarang.

\section{METODE}

Penelitian dengan judul "Analisis Biomekanika Open Smash di Club Bina Taruna Semarang" dilaksanakan pada tanggal 20 oktober 2019 pukul 08.00-10.00 WIB, sesuai jadwal latihan di Club Bina Taruna Semarang. Tempat penelitian berada di gor kedugmundu yang beralamat di Jl. Kedungmundu Raya No. 123a, Tandang Tembalang. Pelaku dalam penelitian ini adalah seluruh atlet club Bina Taruna Semarang yang berjumlah keseluruhan 18 atlet dalam kategori usia 15 tahun. Diambil 10 (sepuluh) atlet laki-laki PBV Bina Taruna Semarang yang berusia 15 tahun sesuai dengan ketentuan peneliti dan pelatih. Teknik penentuan sampel pada penelitian ini menggunakan metode purposive sampling. Alasan pemilihan sampel dengan menggunkan purposive sampling adalah karena tidak semua sampel memiliki kriteria sesuai dengan yang telah penulis tentukan. Oleh karena itu, sampel yang dipilih sengaja ditentukan berdasarkan kriteria tertentu yang telah ditentukan oleh penulis untuk mendapatkan sampel yang representatif. Adapun kriteria yang diambil sebagai sampel adalah: 1). Atlet bola voli Bina Taruna Semarang, 2). Jenis kelamin (gener) laki-laki, 3). Usia sama (usia 15 tahun), 4). Posisi sebagai penyerang (smasher), 5) dipilih oleh pelatih untuk bersedia sebagai sempel. Cara pengambilan sampel dalam penelitian ini yaitu 10 (sepuluh) atlet laki-laki yang memenuhi kriteria tersebut.

Ada dua macam sumber data yaitu data primer dan data sekunder. Dalam Penelitian ini, sumber data primer: berasal dari pengamatan di tempat latihan atau di gor bina taruna kota Semarang dan wawancara mendalam dengan Pelatih klub. Data sekunder: berasal dari perwakilan pemain serta dokumentasi selanjutnya dianalisis.

Analisis data dilakukan menggunakan versi Miles dan Huberman, dalam Sugiyono (2013: 337) bahwa aktivitas dalam analisis data kualitatif dilakukan secara interaktif dan berlangsung secara terus-menerus sampai tuntas sehingga datanya jenuh. Aktivitas meliputi reduksi data (data reduction), penyajian data (data display) dan penarikan kesimpulan (verification). 
Untuk memperoleh suatu kesimpulan dan gambaran masalah yang diteliti. Analisis data merupakan suatu langkah yang penting dalam penelitian. Data rekaman video yang sudah terkumpul tidak berarti apa-apa apabila tidak diolah, karena itu data perlu diamati.

Setelah mendapatkan hasil rekaman video, langkah selanjutnya adalah menganalisis video yang telah diperoleh dengan cara mendeskripsikan hasil rekaman video menggunakan software dartfish. Dartfish versi 4.5.2.0 adalah sebuah software yang pada intinya diperlukan seseorang dalam mengukur sesuatu yang tidak dapat dilihat oleh kejelian mata. Software ini memerlukan sebuah kamera, dan dapat menganalisis gerakan secara kualitatif maupun kuantitatif. Hasil rekaman sebuah gerakan dapat ditayangkan ulang dengan menggunakan Dartfish untuk melambatkan sebuah gerakan dan menghentikan gerakan. Hasil rekaman gambar selanjutnya dapat di transfer kedalam komputer, sehingga rekaman gambar videonya dapat di analisis sesuai kehendak pengamat.

\section{HASIL DAN PEMBAHASAN}

Data penelitian yang diperoleh berasal dari tiga aspek diantaranya: wawancara, observasi, dan dokumentasi berupa video yang dianalisis menggunakan aplikasi software dartfish. Dartfish versi 4.5.2.0 untuk melihat sudut gerakan atlet.

Hasil dari penelitian ini memberikan gambaran bagaimana cara menghasilkan gerakan open smash dalam bola voli dilihat dari teknik dan sudut gerakan dari awalan, backswing, forwardswing, impact dan gerakan follow through yang baik dilihat dari 7 item sudut yang dianalisis yaitu sudut tekukan siku (elbow flexion), sudut bukaan lengan atas (opening the upper arm), sudut kecondongan tubuh (heeling torso), sudut tekukan kaki kanan (right knee flexion), sudut tekukan kaki kiri (left knee flexion), sudut pergelangan tangan (wrist flexion) dan bukaan kaki (leg opening) saat melakukan teknik smash.

\section{Gerakan Persiapan}

Dilihat dari data yang diperoleh secara umum menunjukan keseluruhan atlet PBV Bina Taruna Semarang dalam melakukan persiapan smash belum maksimal dalam melakukanya. Kebanyakan atlet pada saat melakukan gerakan persiapan terlalu terburu-buru, didalam wawancara juga menunjukan semakin optimal geraak langkah akan mendapatkan hasil yang baik, begitu juga di dalam penilian rata-rata gerakan persiapan atlet dalam penilaian dalam kategori (baik) namun belum ada yang dalam penilaian dalam kategori (sangat baik), dari analisis dartfish juga menunjukan belum ada yang sesuai dengan rujukan, rata-rata sudut tekukan kaki kanan (right knee flexion), sudut tekukan kaki kiri (left knee flexion) belum sesuai dengan sudut gerakan yang dilakukan oleh rujukan, dari kesepuluh atlet tersebut masih terlalu terburu-buru sehingga membuat gerakan kurang rileks dan fleksibel serta membuat gerakan jangkauan ancang-ancang yang kurang kuat saat proses gerakan lari menghampiri bola, selain itu sudut gerakan yang dihasilkan masih banyak yang berbeda dengan yang dilakukan oleh rujukan, seharusnya sudut tekukan kaki kanan (right knee flexion) cenderung lebih lurus karena sebagai tumpuan kaki terkuat sebagai awalan dan sudut tekukan kaki kiri (left knee flexion) lebih di tekuk karena sebagai jangkauan kecil dalam melakukan ancang-ancang. Dapat disimpulkan pada saat gerak persiapan atlet PBV Bina Taruna Semarang mengalami ketidak tepatan saat melakukan jangkauan lari menghampiri bola sehingga taming antara gerak bola dan gerak atlet tidak singkron. 


\section{Gerakan Backswing}

Dilihat dari data yang diperoleh secara umum menunjukan bahwa rata-rata atlet PBV Bina Taruna Semarang pada saat melakukan gerakan backswing secara keseluruhan sudah dalam kondisi cukup baik, dalam wawancara pelatih memberikan latatihan lompatan seperti lompat gawang, lompat smash, lopmpat block dll, untuk mendapatkan hasil lompatan yang maksimal. Dilihat dari nilai yang didapat dari instrumen penilaian 5 atet dari sampel sudah melakukan gerakan backswing dengan baik. Selain itu untuk sudut yang dianalisa dari software dartfish tekukan kaki kanan (right knee flexion), sudut tekukan kaki kiri (left knee flexion) dari kesepuluh atlet tidak ada sudut gerakan yang sama dengan rujukan, namun sudah mendekati sudut gerakan yang dilakukan oleh rujukan, terdapat macam-macam sudut tekukan kaki yang dilakukan dari masing-masing atlet. Ada atlet yang sudut tekukan kakinya kurang menekuk $20^{\circ}$ saat melakukan gerakan backswing yang membuat tolakan kaki kurang kuat dan seharusnya posisi kaki lebih menekuk seperti pada rujukan agar lebih maksimal dalam melakukan lompatan. Dari pembahasan gerakan backswing dapat dilihat hasil analisis gerakan backswing atet PBV Bina Taruna Semarang dalam kondisi cukup baik karena lebih dari 50\% dari atlet sampel sudah melakukan lompatan dengan maksimal.

\section{Gerakan Fordwardswing}

Dilihat dari data yang diperoleh secara umum menunjukan bahwa rata-rata atlet PBV Bina Taruna Semarang pada saat melakukan gerakan fordwardswing secara keseluruhan sudah dikatakan baik, dari wawancara menyatakan semakin condong tarikan kebelakang tubuh akan memberikan lecutan yang lebih cepat. Dari data nilai istument penilaian secara keseluruhan atlet dalam penilaian dalam kategori (sangat baik) hanya ada 2 atlet yang dalam penilaian dalam kategori (kurang baik). Dilihat dari analisis software dartfish Sudut kecondongan tubuh (heeling torso) ada 2 atlet yaitu: atlet JP dan MR yang belum maksimal dan berselisih $20^{\circ}$ dengan sudut gerakan yang diakukan oleh rujukan, karena sudut optimal posisi tarikan tubuh kurang menarik kebelakang, sedagkan 8 atlet lainnya gerakan backswing sudah maksimal hanya saja hasil sudut optimal gerakan yang sedikit berbeda dengan yang dilakukan oleh atlet rujukan. Dapat kita lihat dari analisis secara keseluruhan atlet PBV Bina Taruna Semarang sudah melakukan gerakan yang optimal pada saat gerakan fordwardswing, sehingga lecutan untuk menjangkau bola akan lebih cepat dan mendapatkan ayunan untuk memukul bola lebih keras dan hasil yang maksimal.

\section{Gerakan Impact}

Dilihat dari data yang diperoleh menunjukan bahwa rata-rata atlet PBV Bina Taruna Semarang pada saat melakukan gerakan impact secara keseluruhan kurang baik, dari wawancara juga menjelaskan semakin tinggi jangkauan bola dan lecutan tubuh maka hasil pukulan bola akan semakin keras dan maksimal. Dari data nilai instrumen penilian ada 5 atlet yang dalam penilaian dalam kategori (baik) dan 5 atlet lainya dalam penilaian dalam kategori (kurang baik), kebanyakan atlet melakukan pukulan smash terlalu terburu-buru sehingga impact tidak tepat berada di telapak tangan dan lecutan tubuh tidak cenderung condong kebawah sehingga membuat bola tidak menukik dan ada yang menyentuh net. Dilihat dari analisis software dartfish ada 5 atlet yang melakukan jangkauan tangan hampir sama dengan rujukan yaitu atlet $M R, R S, M F, A G$ dan FA jangkauan lebih lurus $10^{\circ}$ sudut dari jangkauan tangan yang dilakukan oleh atlet rujukan, hanya saja ke-5 atlet tersebut 
belum ada dalam kategori (sangat baik) karena kurangnya lecutan tubuh kebawah sehingga gerak bola tidak terlalu menukik. Sedangkan 5 atlet lainya yaitu atlet MF, JP, MK, AP dan WS mengalami pemendekan sudut $20^{\circ}$ dari yang dilakukan atlet rujukan, sehingga kurang tingginya jangkauan membut pukulan tidak maksimal dan ada yang menyentuh net. Dari kesepuluh atlet rata-rata posisi badan tidak membungkuk mengikuti ayunan tangan saat melakukan pukulan seharusnya badan membungkuk kebawah setelah impact ball agar rotasi lebih akurat dan membantu mempermudah gerak bola agar agar keras dan menukik tajam. Dilihat dari analisis gerak imapck ball diatas dapat disimpulkan rata-rata atlet PBV Bina Taruna Semarang melakukan pukulan kurang keras dan kurang menukik saat melakukan pukulan smash.

\section{Gerakan Follow Through}

Dilihat dari data yang diperoleh secara umum menunjukan bahwa rata-rata dari kesepuluh atlet PBV Bina Tarua Semarang pada saat melakukan gerakan follow through keseluruhan dari sudut tekukan kaki kanan (right knee flexion), sudut tekukan kaki kiri (left knee flexion) kurang baik. Dari wawncara menjelaskan pendaratan yang baik menggunakan kedua kaki untuk menjaga atlet dari cidera kaki karena tumpuan dari atas yang cukup keras. Dilihat dari data nilai instrumen penilaian rata-rata atlet dalam penilaian dalam kategori (kurang baik) dan ada 2 atlet yang dalam penilaian dalam kategori (baik) karena kebanyakan atlet mendarat menggunakan salah satu kaki. Dari analisis software dartfish menunjukan banyak atlet yang melakukan pendaratan kurang baik menggunakan tumpuan satu kaki terlebih dahulu saat melakukan pendaratan, hal itu bisa dilihat dari sudut tekukan kedua kaki yang berbeda jauh saat melakukan pendaratan. Dapat disimpulkan saat melakukan pendartan atlet PBV Bina Taruna Semarang kurang begitu baik karena banyak yang menggunakan pendaratan dengan salah satu kaki sehingga saat pendatan tubuh tidak imbang dan ada juga yang tubuhnya masuk ke lapangan lawan.

\section{KESIMPULAN DAN REKOMENDASI}

Hasil dari penelitian ini dapat disipulkan bahwa Dapat disimpulkan atlet PBV Bina Taruna Semarang mampu melakukan gerak smash namun belum maksimal dalam power dan arah tukikan bola, kurangya tinggi jangkauan bola dan lecutan tubuh ke bawah salah satu faktor penyebab kurangnya hasil pukulan smash dan pendaratan yang belum seimbang membuat gerakan smash kurang baik.

Sedangkan dari penelitian dapat diberikan rekomendasi sebagai berikut : (1) Untuk memperbaiki gerakan pukulan open smash, para pelatih diharapkan mampu memberikan arahan dan kritikan kepada atletnya yang bersifat membangun. (2).Untuk memperoleh gerakan pukulan open smash yang maksimal sudut gerakan sangat mempengaruhi, hendaknya dibantu dengan memperhatikan beberapa sudut gerakan yang baik dan benar dalam melakukan pukulan smash, meliputi gerakan sudut tekukan siku (elbow flexion), sudut bukaan lengan atas (opening the upper arm), sudut kecondongan tubuh (heeling torso), sudut tekukan kaki kanan (right knee flexion), sudut tekukan kaki kiri (left knee flexion), sudut pergelangan tangan (wrist flexion) dan bukaan kaki (leg opening) sehingga memberikan hasil pukulan smash yang maksimal pada pukulan open smash dalam bola voli. (3) Untuk meningkatkan gerakan pukulan open smash yang sesuai yakni pukulan yang dilakukan dengan jangkauan lengan paling atas 
yang bertujuan untuk menyerang dengan pukulan open smash yang maksimal. (4) Untuk bahan koreksi dan evaluasi bagi atlet dalam melakukan gerakan open smash yang baik dan benar. (5) Hasil temuan penelitian ini dapat dijadikan sebagai pedoman bagi peneliti yang lain pada situasi atau konteks yang relatif sama di kancah yang berbeda untuk meningkatkan kinerja pelatih

\section{DAFTAR PUSTAKA}

Agus, W, dkk. 2013. Teknik Dasar Permainan Bola Voli. Magelang: Universitas Nergri Magelang. 23-31.

Ari, D.S \& Qiram, I. (2018). "analisis biomekanika jarak langkah take off open spike dalam bola voli". Prosiding seminar nasional IPTEK olahraga, 2018 ISSN 26 22-0156. Diambil dari https://ejurnal.unibabwi.ac.id. Diakses 23 april 2019. 81-83

Beutelstahl. D. (2009). Belajar Bermain Bola Voli. Bandung: Pionir Jaya.

Bonnie Robinson. (1993). Bimbingan Petunjuk dan Teknik Bermain Bola Voli. Jakarta: Dahara Prize.

Irsyamfisio. (2012). Buku Biomekanika -1: gerak manusia dalam perinsip perinsip biomekanika. Diambil dari https://id.scribd.com/doc/80457880/BIOME KANIKA-1. Diakses 24 april 2019. 14-31.

Jaya, Adi. 2018. "Analisa Gerak Lengan (Ekstremitas Superior) terhadap Tingkat Akurasi Servis Panjang Forehand Bulutangkis". Malang: Universitas Negeri Malang.

Mark Man, 2008 dalam (2014). Jurnal of Sport Biomechanics/The Biomechanicsof the Volleyball Spike/ Attack, Diakses 21 agustus 2019.

Muhyi, M, 2007, Meningkatkan kesegaran jasmani melalui permainan dan olahraga bola voli, java pustaka-sport media, Surabaya.

Mutohir, T.C,. 2015. Sececah Harapan Buat Olahragawan. Jakarta: PT. Sunda Kepala Pustaka.
Mutohir, T,C. Dkk. (2012). Permainan Bola Voli, Surabaya: Graha utama media pustaka.

Perkembangan Pendidikan Olahraga. (2018). Biomekanika Olahraga. Jakarta: Uraian Materi-Kb https://www.coursehero.com/file/44415690 /URAIAN-MATERI-kb24pdf/. Diakses 25 april 2019.

Winarno, M.Pd. dkk.(2013). Teknik Dasar Bermain Voli, Malang: Jurusan Pendidikan Jasmai dan Kesehatan Fakultas IImu Keolahragaan Universitas Negri Malang. http://fik.um.ac.id/wpcontent/uploads/2018/02/buku-6.pdf. Diakses 25 april 2019.

Satria, A.A. (2019). Analisis Daya Tahan Anaerobic Pada Peserta Ekstrakulikuler Futsal SMA Institut Indonesia Semarang. Skripsi. Semarang: Universitas PGRI Semarang. Tidak diteritkan.

Sudarmada, Kusuma, W. 2015. Biomekanika Olahraga. Yogyakarts: Graha IImu.

Suharno. H.P (1981). Metodik Melatih Permainan Bola Voli. Yogyakarta: IKIP Yogyakarta. (1979). Dasar-Dasar Permainan Bola Voli. Yogyakarta: IKIP Yogyakarta.

Sugiyono. (2010). Statistik Untuk Penelitian.Bandung:Alfabeta 